\title{
Manufacturing of E-Glass/Epoxy Composite LSU-03 Propeller Using Hand Lay-up Method
}

\author{
A Z Dwi ${ }^{1}$, H Syamsudin ${ }^{2, *}$ \\ 1 Aerospace Engineering, Faculty of Mechanical and Aerospace Engineering, Institut Teknologi Bandung \\ 2 Lightweight Structure Group, Faculty of Mechanical and Aerospace Engineering, Institut Teknologi \\ Bandung, Jalan Ganesha 10 Bandung \\ * Correspondence: hendri.syamsudin@ae.itb.ac.id
}

Received: 21 July 2020; Accepted: 12 October 2020; Published: 20 December 2020

\begin{abstract}
Hand lay-up method is frequently used by small companies. It is due to its flexibility and low-cost considerations. One of the qualities problems that normally arises is the product unevenness. This study was carried out to analyse this variation on manufacturing E-glass/epoxy plates specimen and propeller product. Void and fibre volume fraction of manufactured plates are measured based on ASTM-D2734. Propellers of LSU-03 aircraft were manufactured and analysed to find out the uniformity of the product in terms of its mass and size. To determine product compatibility with the design, the geometry and the thickness were measured at several points of propeller. In addition to this, a balancing process is carried out to find out the mass balance point.
\end{abstract}

Keywords: propeller, hand lay-up , composite, balance point

\section{Introduction}

Hand lay-ups (HLU) are commonly considered as the simplest composite manufacturing method. However, it has disadvantages such as, HLU produces products with relatively average results in terms of its quality and performance. The maximum HLU fiber volume fraction is at $40 \%$ if the lay-up process is done manually, whilst combined with pressure and heating during curing process, the fiber volume can reach almost $50 \%$ [1]. HLU has also problems with uniformity and consistency of products. For high performance products, an operational standard is needed to obtain uniform products. In this study, the manufacturing process will be carried out for producing LSU-03 aircraft propellers. The amount of fiber and resin volume fraction obtained from the process is measured and compared. This process is carried out several times with the aim to measure the variation of final mass and geometry of the propellers.

There are only few studies on HLU manufacturing methods because the production parameters are greatly depending on the operators that carry out the production process. Several studies have been conducted on the variation of the product quality, produced by operators with various backgrounds. Kikuchi et al. explain an experiment with operators with different experiences to make a plate with a certain configuration [2]. The result shows that operators who have longer experience do not necessarily perform layup work faster and produce better products. This result shows that HLU process inconsistency problem is not with the operator, but rather with the operational standards carried out. In the study, there was no standard procedure enforced, instead they gave the operator the freedom to perform the layup process as they knew. So that it is possible for operators who have no experience when doing the second, third, and so on layup processes will vary. While operators who have experience may be able to produce products that are quite consistent [3]. 
In this study, the production operator is the same person. In the manufacturing process, the amount of fiber and resin used is maintained the same. It is a study of the influence of operators on product variation.

\section{Materials and Methods}

\subsection{Design and Material of Propeller}

The type of fiber used is E-glass fiber cloth 135 and the resin used is Lycal 1011. The dimensions of the propellers are the same as existing conventional wood propellers, as presented on Figure 1.

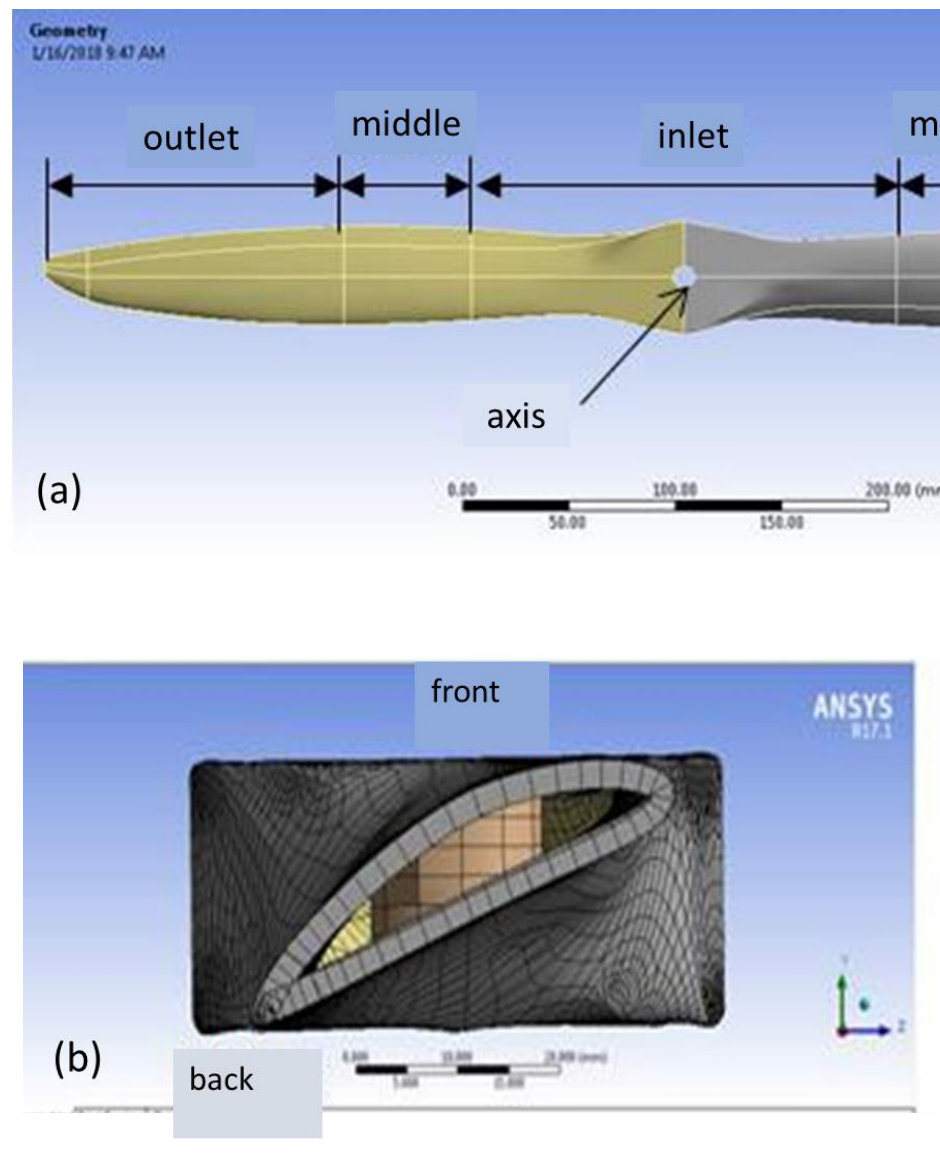

outlet

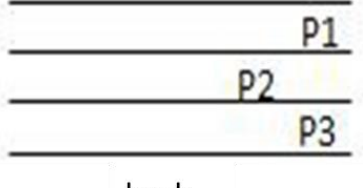

back

Figure 1. Composites Propeller: (a) Design and (b) Cross section

Table 1. Composites Propeller Design Configuration

\begin{tabular}{ccccccc}
\hline \multirow{2}{*}{ Section } & $\begin{array}{c}\text { Orientation } \\
\text { Type }\end{array}$ & Lamina & \multicolumn{5}{c}{ Number of layers } \\
\cline { 3 - 6 } & & & Centre & Inner & Mid & Outer \\
\hline $\mathbf{P 3}$ & \pm 45 & E-glass- & 1 & 1 & 1 & 1 \\
\hline $\mathbf{P 2}$ & 0 & E-glass- & 15 & 10 & 5 & 2 \\
\hline $\mathbf{P 1}$ & & & 1 & 1 & 1 & 1 \\
\hline
\end{tabular}




\subsection{Design Manufacturing Process}

In this study, two LSU-03 propellers were manufactured. The HLU manufacturing process is carried out by laying-up a layer of fibre fabric and then smeared with resin. When the fibre is fully wetted, then the process is repeated until it reaches the number of layers as specified in the design. The amount / weight of fiber and resin prepared for the two manufactured products are kept the same. The number of fiber layers follows the configuration in Table 1. The amount of resin the total weight of the fiber used, as presented on Figure 2.

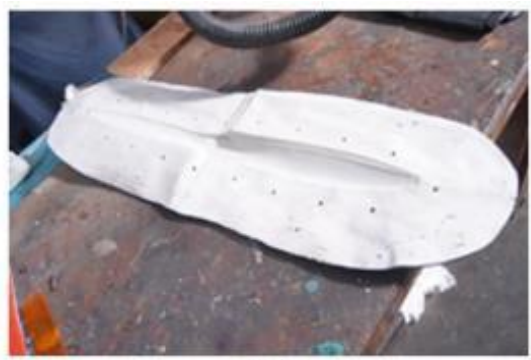

(a)

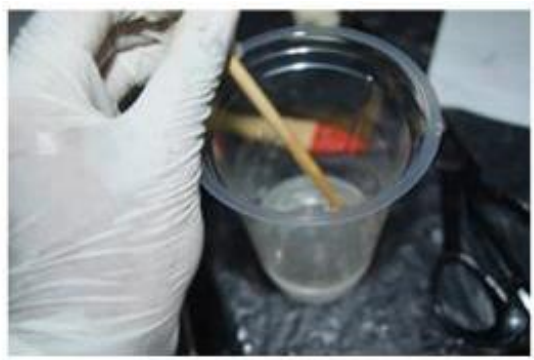

(c)

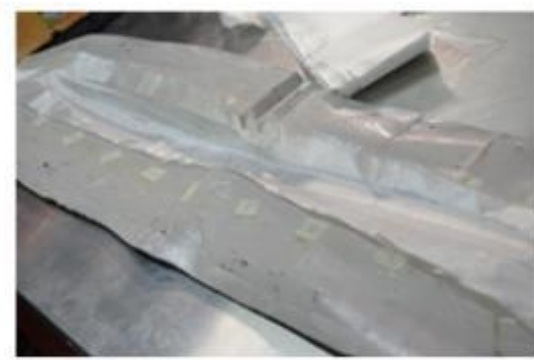

(b)

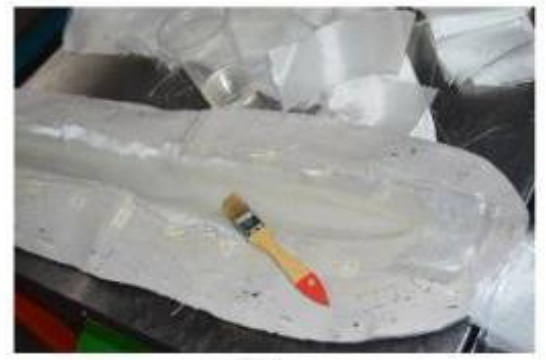

(d)

Figure 2. HLU Process: (a) Preparation, (b) Lay-up, (c) Resin mixing, and (d) Impregnation

\subsection{Assembly}

The assembly process is done after the upper and lower parts of the propeller have hardened. The assembly is done by combining the upper and lower parts with the connection at the Trailling Edge (TE) and Leading Edge (LE). The material used is the same e-glass fibre-epoxy composite of \pm 45, as on Figure 3.

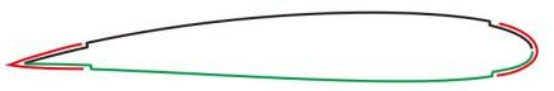

Figure 3. Joining design at TE and LE

\section{Results and Discussions}

\subsection{Assembly}

The assembly process is carried out after cutting the upper and lower parts. The main problem in the assembly process is to make sure both sides of the propeller fit together according to the initial design form, so that the final geometry matches the design. This problem originated from the method of cutting parts. Some possible cuts can be seen in the Figure 4 . 


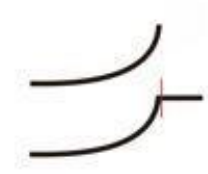

(a)
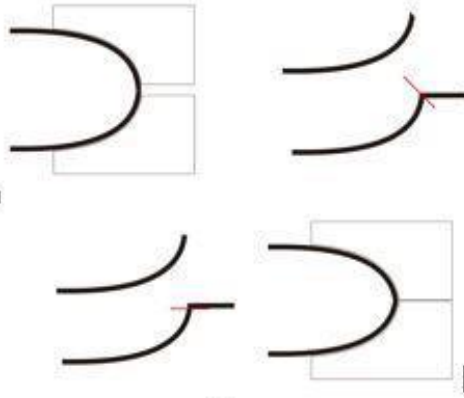

(c)

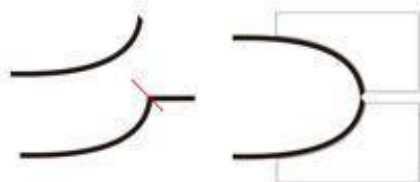

(b)

Figure 4. Cutting mechanism: (a) Poor, (b) Poor, and (c) good

In fact, the most likely cut is sloping cutting (point b). As a result of this model cutting is the thickening of almost all parts of the propeller. As a result, there are differences in propeller aerodynamic attitudes.

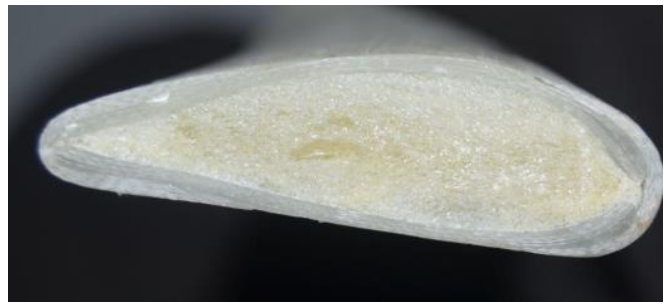

Figure 5. LE and TE after joining

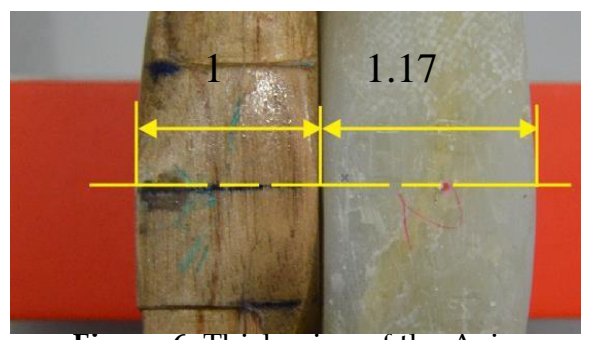

Figure 6. Thickening of the Axis

Assembly results show poor results. There is still thickening in the connection section (LE and TE). This happens because the number of layers in the connection is too much, as mentioned in the agreement with others [3,4].

\subsection{Propeller Mass}

The propeller mass is measured when the propeller has gone through an assembly and finishing process so that the mass is the final mass / ready-to-use product. Of the two propellers made, the mass measurements did not show significant results. See Figure 7 for propeller products and Figure 8 for mass measurement. P1 is the first product while P2 is the second product.

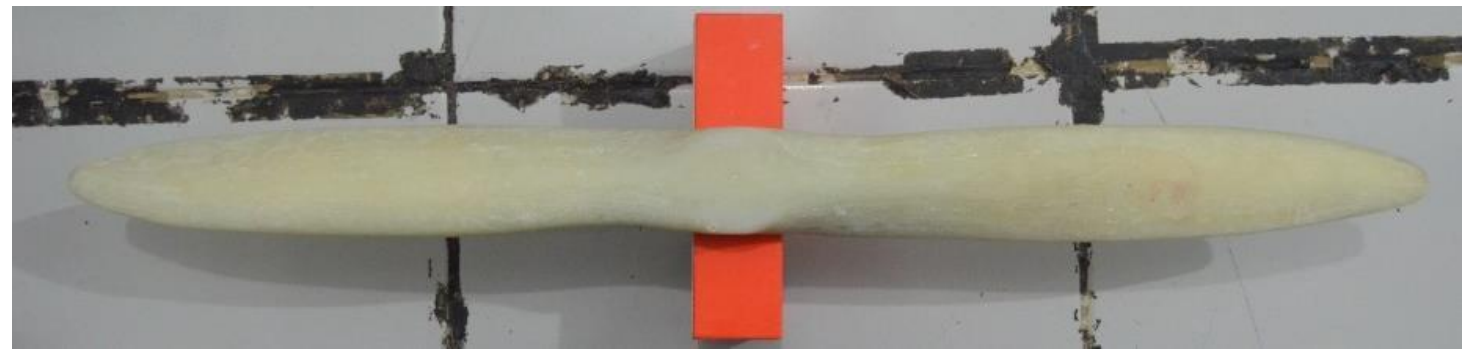

Figure 7. Propeller product

Table 1. Propeller mass

\begin{tabular}{lcl}
\hline & P1 & P2 \\
\hline Massa (gram) & 248 & 252 \\
\hline
\end{tabular}




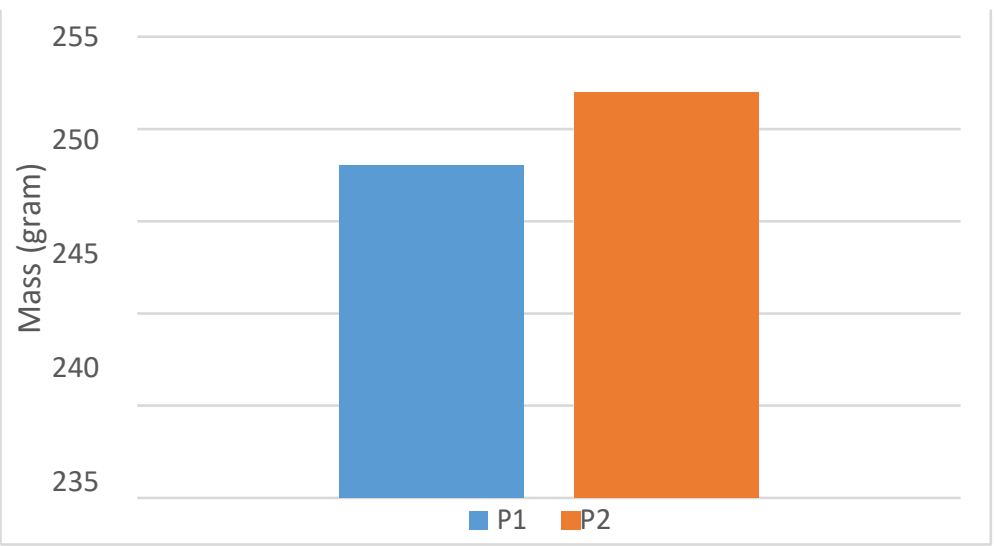

Figure 8. Propeller mass

\section{Conclusions}

The results show that the propeller has little weight variation of $1.6 \%$. It is achieved with a good production procedure. It is important to focus on the amount and weight of resin and fiber used to produce uniform products. With the production standard, there is less random variables due to operators so that the product quality can be maintained.

\section{Acknowledgments}

The authors would like to acknowledge the financial support from Ministry of Research, Technology and Higher Education (Kemenristekdikti) Indonesia under the scheme of Penelitian Terapan Unggulan Perguruan Tinggi, 2018.

\section{References}

1. A F Avila and D T S Morais, 2005, A Multiscale Investigation Based on Variance Analysis for Hand Lay-up Composite Manufacturing. Composites Science and Technology. 65 825- 838.

2. T Kikuchi, H Hamada, A Naki, A Ohtani, A Goto, Y Takai, A Endo, C Narita, T Koshino, and A Fudauchi, 2013, Process Analysis of Hand Lay-up Method by Various Experience Persons. The 19TH International Conference on Composite Materials.

3. A Nuranto, 2018, Simulasi dan Analisis Desain Struktur Baling Baling Pesawat LSU-03 menggunakan Material Komposit (Bandung: Institut Teknologi Bandung).

4. A R Nuranto, A J Fitroh and H Syamsudin, 2018, Analysis of Aerodynamic Load of LSU-03 (LAPAN Surveillance UAV-03) Propeller, Journal of Physics: Conf. Series 1005 (2018) 012008, pp. 1-10. 